\title{
Editorial: Announcing The Journal of Open Law, Technology \& Society
}

DOI: 10.5033/jolts.v11i1.134

by The Editorial Committee, coordinated by Shane Coughlan. ${ }^{a}$

(a) OpenChain Project Director, Linux Foundation.

\begin{abstract}
This editorial article by the Editorial Committee of the Journal of Open Law, Technology \& Society announces the change in name, and expansion in scope, of the International Free and Open Source Software Law Review.

\section{Keywords}

Law; information technology; governance; Free and Open Source Software; International Free and Open Source Software Law Review; Journal of Open Law, Technology \& Society; JOLTS.
\end{abstract}

\begin{abstract}
When the International Free and Open Source Software Law Review was launched in 2009, we stated that it was our "hope and expectation that it will provide a centre of excellence for the very best in analysis of issues facing users and advisors in the development, deployment and governance of Free and Open Source software...." Since then, the International Free and Open Source Software Law Review has had a storied history in the realm of free and open licensing around software technology. While the law review was initially inherently biased towards a relatively small audience, we have been fortunate to both gain readership and provide value to this audience over a period of more than 10 years. Many things have changed since we published our first issue in 2009. At that time, open source was still gaining traction in the business and legal spheres. Notwithstanding the exceptional success of service companies such as IBM and HP in the preceding decade, and the continued rise of "open source" companies such as Red Hat, in 2009 general awareness across multiple market segments of free and open source software and the licensing models behind it were still relatively low. That is no longer the case. The rise and tremendous success of companies like Google, Facebook and Uber is predicated on a foundation of free and open software. Platforms once unobtainable to all but the largest companies are now within the reach of even the smallest start-up, and we are seeing a terrific explosion of new services, products and business models as a consequence.
\end{abstract}

Free and open source software has moved from "emerging" to "market dominant." Indeed, free and open source software has been such a success that it has inspired an adjacent explosion of broader and increasingly visible open hardware, open access, open data and open knowledge initiatives across

1 Mitchell, Iain G. (2009) 'Foreword and statement of purpose: an introduction to IFOSS L. Rev.', IFOSS L. Rev, 1(1), p. 
the globe. In acknowledgement and in celebration of this expansion of open models, the editorial committee of IFOSSLR is taking steps to position our publication and our community for continued relevance to technical, business and legal professionals operating in these expanded areas. The freedom and openness that brings success in markets, in revenue and in social development is no longer confined to software and neither should this journal be so confined. We are delighted to announce an expansion of our scope and a further broadening of our audience and community. Welcome to JOLTS, the Journal of Open Law, Technology \& Society, a publication intended to help you stay abreast of the most interesting and most relevant topics emerging in our sphere. We look forward to continued collaboration with you and with your peers.

\section{About the author}

Shane Coughlan is the OpenChain Project Director for the Linux Foundation and an editor of this Journal.

\section{Licence and Attribution}

This paper was published in the Journal of Open Law, Technology, \& Society, Volume 11, Issue 1(2019). It originally appeared online at http://www.jolts.world

This article should be cited as follows:

Coughlan, Shane et al (2019) 'Editorial: Announcing The Journal of Open Law, Technology \& Society', Journal of Open Law, Technology \& Society, 11(1), pp 1 - 2 DOI: $10.5033 /$ jolts.v11i1.134

Copyright (C) 2019 Jolts.

This article is licensed under a Creative Commons Attribution 4.0 CC-BY available at https://creativecommons.org/licenses/by/4.0/

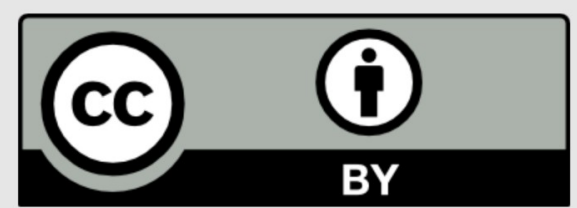

